\title{
Art Déco e publicidade: a descaracterização do patrimônio moderno de Passo Fundo/RS
}

\author{
Art Deco and publicity: the mischaracterization of the modern \\ heritage of Passo Fundo/RS
}

Art Deco y publicidad: la alteración del carácter del patrimonio moderno de Passo Fundo/RS

\author{
DINIZ, Pedro Henrique Carretta ${ }^{1}$ \\ ALMEIDA, Caliane Christie Oliveira de ${ }^{2}$ \\ 1 e 2 Faculdade de Arquitetura e Urbanismo, Faculdade Meridional (IMED), Passo Fundo, Brasil. \\ phenriquecd@gmail.com \\ ORCID ID: 0000-0001-6726-3380 \\ caliane.silva@imed.edu.br \\ ORCID ID: 0000-0002-8477-389X
}




\title{
Resumo
}

Este artigo se insere na temática da publicidade e do patrimônio histórico, tendo como foco a cidade de Passo Fundo/RS, Brasil. Objetivou-se identificar e mapear as edificações com referência ao Art Déco na cidade, bem como analisar o impacto dos anúncios publicitários neste patrimônio moderno. Para tanto, foi preciso realizar estudos bibliográficos relacionados às temáticas da publicidade, do Art Déco e do processo de formação e transformação de Passo Fundo, com o intuito de entender a importância da mencionada linguagem arquitetônica no contexto da cidade e expor o poder de descaracterização que a falta de normatização publicitária exerce nas edificações de valor histórico. Também foram realizados levantamentos in loco dos exemplares Déco identificados, bem como levantamentos documentais de leis municipais relacionadas ao patrimônio e ao controle publicitário em vigor no Brasil. Grande parte das edificações identificadas estão em ruim ou péssimo estado de conservação e possuem anúncios excessivamente grandes e despadronizados, comprometendo a percepção do léxico arquitetônico e, consequentemente, seu valor histórico e cultural.

Palavras-Chave: Art Déco; Publicidade; Preservação; Passo Fundo.

\begin{abstract}
This paper is part of the theme of advertising and historical heritage, focusing on the city of Passo Fundo/RS, Brazil. The objective was to identify and map the buildings with reference to the Art Déco in the city, as well as to analyze the impact of the advertisements in this modern patrimony. In order to do so, it was necessary to carry out bibliographical studies related to the themes of publicity, Art Deco and the process of formation and transformation of Passo Fundo, in order to understand the importance of the mentioned architectural language in the context of the city and to expose the power of the lack of publicity regulation exerts on buildings of historical value. There were also on-site surveys of the identified Déco buildings, as well as documentary surveys of municipal laws related to patrimony and advertising control in force in Brazil. Most of the identified buildings are in bad or bad condition and have ads that are too large and unadjusted, compromising the perception of the architectural lexicon and, consequently, its historical and cultural value.to understand the cinematographic representation of a space it is necessary to investigate the filmic frame, being aware that it presupposes a relationship between body, space and camera.
\end{abstract}

Key-Words: Art Déco; Publicity; Preservation; Passo Fundo.

\section{Resumen}

Este artículo es parte del tema de la publicidad y el patrimonio histórico, y se centra en la ciudad de Passo Fundo / RS, Brasil. El objetivo era identificar y mapear los edificios con referencia al Art Deco en la ciudad, así como analizar el impacto de la publicidad en este patrimonio moderno. Por lo tanto, fue necesario realizar estudios bibliográficos relacionados con los temas de publicidad, Art Deco y el proceso de formación y transformación de Passo Fundo, para comprender la importancia del lenguaje arquitectónico mencionado en el contexto de la ciudad y exponer el poder de la caracterización errónea que la falta de reglas para la publicidad provoca en los edificios de valor histórico. También se realizaron búsquedas in situ de los edificios Déco identificados, así como levantamientos documentales relacionados con el patrimonio y el control publicitario vigentes en Brasil. La mayoría de los edificios identificados están en malas o muy malas condiciones y tienen anuncios excesivamente grandes y sin estándar, comprometiendo la percepción del léxico arquitectónico y, en consecuencia, su valor histórico y cultural.

Palabras-Clave: Art Déco; Publicidad; Preservación; Passo Fundo. 


\section{Introdução}

As cidades brasileiras fundadas no intervalo de tempo entre a chegada dos portugueses e a Independência do Brasil (1500-1822) possuíam uma conformação urbanística específica. O zoneamento espacial se dava, essencialmente, em torno de uma Igreja que geralmente estava voltada à praça central, bem próxima às edificações representativas de poder, às moradias dos mais abastados e pontuais estabelecimentos comerciais. Com o desenvolvimento econômico, esses pequenos núcleos urbanos passaram naturalmente a ter uma maior vocação mercantil, e assim foram se conformando os primeiros centros comerciais no país. Nesse contexto, a publicidade se tornou algo inerente à prática varejista, podendo-se afirmar, salvo as devidas proporções, que ela está presente desde o período do Brasil Colônia, desenvolvendo-se junto ao referenciado crescimento econômico e à expansão da prática comercial em nossas cidades.

Vale salientar que, na língua portuguesa, o termo "publicidade" é comumente interpretado como sinônimo de "propaganda", por mais que essas duas definições possuam significados diferentes. Em linhas gerais, as mensagens publicitárias visam predispor seu público alvo à realizar uma ação rápida, como a compra de um carro ou de uma viagem, por exemplo. Já a propaganda, por sua vez, não almeja a realização de ações individuais e imediatas, mas sim a mudança das atitudes de um público em relação a uma ideia (SANTOS, 2005; AMBRÓSIO e ZALITE, 2018).

A cidade de Passo Fundo está localizada no noroeste do estado do Rio Grande do Sul, e o cenário citadino, sobremaneira o seu centro histórico e comercial, se apresenta composto por muitas edificações com características Art Déco. Trata-se de uma região bastante verticalizada e com grande diversidade de usos, que passa por um processo de valorização no mercado imobiliário e que, dessa maneira, está submetida aos interesses especulativos. Diante desse cenário, diversas construções estão, em suma, fadadas à descaracterização e à perda de identidade, também provenientes da inexistência de legislação regulamentadora da atividade publicitária, assim como da falta de discussões acerca da salvaguarda dos prédios de valor histórico e cultural da cidade.

Ressaltando a importância da pesquisa, a problemática deste artigo envolve a não identificação ou reconhecimento das edificações Art Déco como parte do patrimônio histórico e da paisagem cultural ${ }^{1}$ de Passo Fundo. A atividade publicitária, aliada às mudanças de uso promovidas pela especulação imobiliária e ao processo de verticalização da cidade - intensificado nos anos 1990 e em curso até os dias atuais -, contribuem significativamente para que este patrimônio sofra abandono, modificações, reformas e/ou completa descaracterização, chegando ao extremo da demolição, sem sequer ser registrado; quadro similar ao vislumbrado em diversas cidades brasileiras, como colocado por Correia (2008), Salvador (2012), Tirello e Costa (2017), Ambrósio e Zalite (2018) e Citron, Mendes e Talamini (2018).

Apesar de Passo Fundo possuir grande representatividade econômica regional, em se tratando de estudos socioespaciais e de referências arquitetônicas, a cidade ainda pode ser considerada pouco analisada. A historiografia local se deteve, mormente, em estudar os processos de ocupação do seu território e a influência dos imigrantes europeus nesse contexto. Os pontuais referenciais teóricos a respeito do patrimônio moderno de Passo Fundo apontam seu valor histórico e trazem estudos de caso de algumas edificações na cidade, a exemplo de Lech, Czamanski e Czamanski (1999), Machado e Miranda (2005), Lorenzi, Gonçalves e Piccinato Junior (2018) e Lorenzi e Piccinato Junior (2019). No

\footnotetext{
${ }^{1} \mathrm{O}$ termo Paisagem Cultural define um território, tal como é apreendido pelas pessoas, cujo caráter resulta da interação entre fatores naturais e a ação humana ao longo do tempo, e que está em constante transformação (FOGAÇA, 2019). Desse modo, as edificações Art Déco estudadas, que possuem valor histórico e são frutos da ação humana, fazem parte da construção da paisagem cultural de Passo Fundo.
} 
entanto, não existe nenhuma pesquisa que envolva a questão do patrimônio moderno, em especial a arquitetura Art Déco, e a publicidade e propaganda no contexto passofundense. Nesses aspectos que a pesquisa ora apresentada se justifica e é contextualizada.

Nesse sentido, este artigo tem como objetivo identificar e mapear as edificações que remetem ao léxico Art Déco na cidade de Passo Fundo, bem como analisar o impacto das diferentes formas de publicidade e propaganda neste patrimônio arquitetônico moderno, a fim de explicitar a descaracterização promovida por essa atividade na localidade.

Acerca dos procedimentos metodológicos, o artigo foi desenvolvido em três principais etapas: pesquisa bibliográfica, pesquisa documental e pesquisa em campo. Primeiramente, utilizou-se de estudos bibliográficos da área da Publicidade e Propaganda, com base nos textos de Silva e Lopes (2007) e Ambrósio e Zalite (2018), a fim de contextualizar as características, o surgimento e o desenvolvimento das diversas formas de publicidade no Brasil. Abordou-se a temática do Art Déco sob a perspectiva de Correia (2008) e Pissetti e Souza (2011), e fez-se um estudo do processo de formação e transformação de Passo Fundo por meio, principalmente, dos trabalhos de Gosch (2002) e Ferretto (2012), com o intuito de compreender a importância do mencionado vocabulário arquitetônico nesse contexto. Posteriormente, realizou-se o levantamento documental de legislações municipais que regulamentam a instalação de anúncios publicitários, sobretudo nas fachadas de prédios históricos, objetivando exemplificar meios pelos quais o poder público pode intervir na salvaguarda do seu patrimônio construído. A terceira etapa, por sua vez, compreendeu os levantamentos in loco e os registros fotográficos das edificações Art Déco de maior relevância do centro comercial passofundense. Uma vez identificadas, fez-se o mapeamento, o registro dos elementos que compõem o léxico Art Decó e o diagnóstico das descaracterizações promovidas pela atividade publicitária.

Identificando, mapeando e analisando o impacto da atividade publicitária nos prédios Art Déco de Passo Fundo, espera-se que este artigo contribua para a valorização dessa arquitetura e, ainda, corrobore para a elaboração e outorga de legislação regulamentadora da publicidade com base nas experiências de outros municípios brasileiros.

\section{A publicidade no Brasil: aspectos históricos e atuais}

Segundo Silva e Lopes (2007), a publicidade no Brasil surgiu no período de colonização, na forma oral. Aos poucos, anúncios escritos passaram a ser encontrados em classificados de jornais e apresentavam linguagem simples, sem técnicas de persuasão. Apenas por volta dos anos de 1900, as características da linguagem publicitária brasileira começaram a mudar, incorporando elementos como a sátira política por meio de caricaturas e versos bem-humorados.

Os avanços tecnológicos colocaram o rádio no cenário publicitário brasileiro, período conhecido como era dos jingles, que se tornaram cada vez mais populares a partir dos anos de 1930. Na época, também se consolidaram as primeiras associações da classe publicitária, como a Associação Brasileira de Propaganda (ABP) e a Associação Paulista de Propaganda (APP). Contudo, o grande marco na história da publicidade foi o advento da televisão. Esse foi um passo singularmente importante na transformação do cenário publicitário, que se desenvolveu rapidamente após os anos 1950 e trouxe consigo as primeiras escolas de propaganda e de comunicação do país (SILVA e LOPES, 2007).

Deste modo, pode-se afirmar que a publicidade acompanhou o desenvolvimento tecnológico e se transformou de modo a estar cada vez mais presente no dia-a-dia das pessoas. Nota-se, entretanto, que uma das maneiras mais utilizadas de se propagar um serviço, um produto ou uma ideia, nas zonas comerciais das cidades brasileiras, ainda se materializa em placas, letreiros e luminosos nas fachadas das edificações. 
Conforme Ambrósio e Zalite (2018), as fachadas e vitrines das edificações - sejam elas históricas ou não -, são muito utilizadas como forma de atração de clientes. As autoras também destacam que a aparência dos estabelecimentos tem o poder de causar diferentes impactos visuais e psicológicos nos consumidores, fato determinante na tomada de decisão de compra por parte da população. Sendo assim, a falta de conhecimento acerca dos efeitos da publicidade pode resultar em fachadas e vitrines com sérios problemas de poluição visual ${ }^{2}$, o que acarreta, em muitos casos, na desvalorização do estabelecimento e da edificação, comprometendo a paisagem de nossas cidades.

Brenner, Marostega e Almeida (2017) ressalvam que, nos dias de hoje, a atividade publicitária tem causado danos às cidades no que diz respeito à qualidade da paisagem urbana. Por vezes, os anúncios estão dispostos de forma desregulada, comprometendo a identificação das edificações, principalmente de valor histórico. Entretanto, a solução para esse fenômeno não passa por impedir a instalação de anúncios publicitários, mas sim por encontrar uma maneira que as mídias externas se relacionem de forma sustentável e honesta com o espaço público, respeitando a cultura, a identidade local e o planejamento urbano das cidades.

Nesse contexto, grande parte da bibliografia especializada, a citar os autores supramencionados, defende que o impasse entre a publicidade e a preservação da paisagem de nossas cidades se dá no momento em que não há uma regulamentação das atividades publicitárias. Em se falando das edificações Art Déco de Passo Fundo, a falta de legislação pertinente acaba permitindo que a identidade visual desses testemunhos históricos se perca entre placas, outdoors, letreiros e outras formas de anúncios. Por outro lado, existem exemplos de leis municipais, já sancionadas e em vigor, que podem servir como base para a criação de uma lei específica para Passo Fundo, como se verá no item a seguir.

\subsection{Legislações regulamentadoras da publicidade: os casos de São Paulo (SP), Erechim (RS) e Bento Gonçalves (RS)}

A municipalidade possui muitas maneiras de intervir na normalização publicitária em prol da salvaguarda de edificações, principalmente daquelas com valor histórico e cultural. Levando isso em consideração, destaca-se a Lei Municipal ํo 14.223 de 2006, da capital paulista, que dita regras para a colocação de anúncios indicativos nas fachadas dos imóveis públicos e privados. A partir de 2007, ano em que a lei entrou em vigor, ficou determinado que cada estabelecimento somente pode possuir entre um e dois anúncios padronizados, dependendo da extensão da fachada. Para prédios considerados de pequeno porte, com testada de até 10 metros, o anúncio não pode ter uma área maior que $1,5 \mathrm{~m}^{2}$. Esse valor aumenta proporcionalmente com o tamanho do edifício. Em último caso, o proprietário ou locatário do estabelecimento pode recorrer ao poder público para a fixação de dois anúncios, caso a testada deste seja superior a $100 \mathrm{~m}$ lineares. Além disso, por meio da supramencionada legislação municipal ficou proibida a instalar qualquer tipo de anúncio publicitário que oblitere, mesmo que parcialmente, a visibilidade dos bens tombados ou que prejudique a edificação em que estiver instalado e seu entorno (SÃO PAULO, 2006).

Cinco anos após a referida lei entrar em vigor, a prefeitura municipal de São Paulo recebeu o selo europeu "Werkbund" em reconhecimento aos resultados. O prêmio é concedido a cada dois anos pela Federação Alemã de Obras do estado de Baden-Wurttemberg e seleciona iniciativas que se destacam pela inovação, pelo engajamento social e pelo respeito à natureza. Esta foi a primeira vez que o selo

\footnotetext{
${ }^{2}$ A poluição visual pode ser considerada um conjunto de elementos que causam a depreciação da paisagem das nossas cidades, transformando o ambiente urbano de forma desordenada e o tornando desarmônico (GOMES et al., 2019).
} 
foi concedido à alguma cidade fora do território alemão (PORTAL DA PREFEITURA DE SÃO PAULO, 2012).

No estado do Rio Grande do Sul, existem duas leis municipais que podem ser consideradas exemplos para as demais cidades no que diz respeito à padronização publicitária urbana. A primeira delas foi outorgada em Erechim, um município da região do Alto Uruguai, apresentando aspectos comuns à legislação paulista. A Lei municipal "Erechim, Cidade Limpa" (Lei $n^{\circ}$ 6.093), de 2015, tornou-se um marco importante no processo de requalificação do centro comercial e histórico do município. Em linhas gerais, de acordo com o mencionado documento, todo anúncio indicativo em edificações de cunho comercial deve observar, dentre outros, o seguinte critério básico: não prejudicar a integridade nem a visualização das edificações, principalmente as de valor histórico e cultural.

Além disso, essa normatização ainda proíbe qualquer tipo de adesivação nas vitrines de edificações históricas. Banners e outros anúncios de mesma natureza, só são permitidos dentro do estabelecimento, a no mínimo $1,00 \mathrm{~m}$ de distância da vitrine. Por fim, adesivos em fachadas não históricas deverão igualmente passar por análise do Conselho Municipal de Patrimônio Histórico, Artístico e Cultural, o COMPHAC, quanto a sua permissividade ou não, caso esses prédios estejam no entorno de edificações de caráter histórico no raio delimitado pelo Plano Diretor vigente (ERECHIM, 2015).

Assim como em São Paulo, a Lei n.6.093 também dita as dimensões dos anúncios indicativos permitidos. Mais precisamente, para edificações consideradas de pequeno porte, ou seja, com no máximo $5 \mathrm{~m}$ de testada, o anúncio não deve ultrapassar $0,75 \mathrm{~m}^{2}$ em área. Esta dimensão aumenta proporcionalmente com a edificação, podendo chegar a $5 \mathrm{~m}^{2}$ para imóveis com testada superior a $50 \mathrm{~m}$ lineares (Figura 1). No que tange às cores permissíveis de serem empregadas nos tratamentos de fachada, a legislação ainda determina, entre outros aspectos, que adornos e detalhes arquitetônicos como aberturas, molduras, balaústres e cornijas devem ser destacados por meio da utilização de revestimentos na cor branca ou em tonalidade diferenciada da mesma aplicada na maior parte da fachada, respeitando a paleta de cores sugerida no mesmo texto (ERECHIM, 2015). 
Figura 1: ilustração demonstrativa dos tamanhos e de como devem ser fixados os letreiros em prédios históricos no município de Erechim. O exemplo abaixo é para uma edificação com testada entre 10 e $20 \mathrm{~m}$. Neste caso, o tamanho dos letreiros não deve ultrapassar $2 \mathrm{~m}^{2}$ (somados). O texto da Lei "Erechim, Cidade Limpa" possui 18 ilustrações como esta, criadas para facilitar o entendimento e a aplicabilidade das dimensões e cores permitidas.

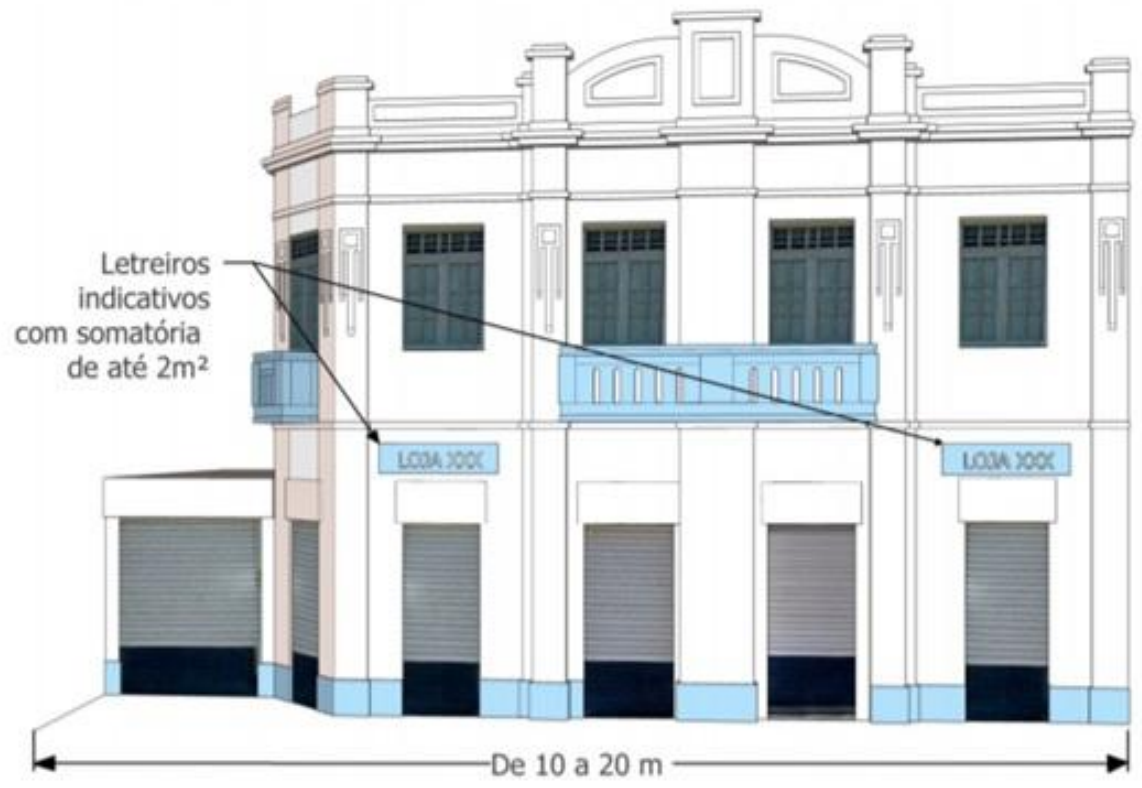

Fonte: ERECHIM, 2015, p.9.

Outro exemplo sul-rio-grandense de normatização para letreiros publicitários é a Lei n 5.871 de 2014 , outorgada pela Prefeitura Municipal de Bento Gonçalves, uma cidade situada na região serrana do estado. Essa legislação também determinou a padronização das dimensões dos letreiros, placas e outdoors nos imóveis de valor histórico da cidade. Ademais, a Lei fracionou a malha urbana de Bento Gonçalves em cinco zonas: ZP1 (Zona Publicitária 1), ZP2 (Zona Publicitária 2), ZPMUV (Zona Publicitária Mobiliário Urbano e Verde), ZP DAER (Zona Publicitária DAER RST 470 e RS 444) e ZPI (Zona Publicitária Institucional). Cada uma delas possui particularidades e padrões diferentes de anúncio. Apenas na ZP2, por exemplo, permite-se a utilização de painéis digitais que poderão permanecer ligados entre os horários das $6 \mathrm{~h}$ da manhã até as $23 \mathrm{~h}$ e $59 \mathrm{~min}$ da noite (BENTO GONÇALVES, 2014).

Percebe-se, com esses exemplos, que a municipalidade possui o poder de ditar as regras pertinentes à normatização de letreiros publicitários e a conservação do patrimônio histórico construído. Em se tratando das construções de caráter Déco na cidade de Passo Fundo, esta é uma das formas mais eficazes de se criar uma cultura de valorização, cuidado e preservação desse patrimônio, bem como de desenvolver um senso estético perceptível por parte da população.

\section{O movimento Art Déco}

Em linhas gerais, o movimento "Art Déco" ganhou força a partir de meados dos anos de 1920, essencialmente nos países europeus e nos Estados Unidos, e é tido por parte da historiografia especializada como a referência arquitetônica que marca o início do chamado período moderno ${ }^{3}$ em alguns países (CORREIA, 2008). Apesar de não ter sido caracterizado como um evento específico de exposição Art Decó, o termo faz alusão à Exposição de Artes Decorativas e Industriais Modernas,

\footnotetext{
${ }^{3} \mathrm{Na}$ arquitetura, o período moderno teve início nas primeiras décadas do século $\mathrm{XX}$. Mais especificamente, no Brasil, tem-se a Semana de Arte Moderna de 1922 como um importante marco para o movimento, cuja maior expressão se deu entre os anos 1930 e 1950 (NASCIMENTO, 2011).
} 
realizada em Paris no ano de 1925. Naquela ocasião, o termo foi utilizado pela primeira vez para designar projetos de decoração de interiores, estamparia, tapeçaria, cerâmica, vidro, joias, artefatos de metal, esculturas e luminárias (PISSETTI e SOUZA, 2011).

A simplificação de elementos decorativos e a diversificação de fontes de influência ornamental também é um dos principais aspectos e um dos mais inovadores da arquitetura Art Déco. Nesse sentido, podese incluir aos elementos característicos dessa arquitetura a incorporação de referências às máquinas a vapor e aos navios, principalmente. Alusões às construções egípcias e astecas também estão presentes, representadas no geometrismo, no uso de prismas ortogonais, no escalonamento e na sobreposição de planos nas fachadas (CORREIA, 2008).

Em se tratando da América Latina, o Art Déco se caracterizou como a transição entre os princípios das escolas de Belas Artes e o racionalismo da nova arquitetura que estava surgindo, praticamente eliminando seus vínculos classicistas e sua linguagem historicista, mas mantendo elementos como simetria e utilização de ornamentos decorativos aplicados, mesmo que simples e em pouca quantidade (VENTURINI e LIMA, 2009), como pode ser observado na arquitetura que apresenta esta referência em Montevidéu, Rio de Janeiro, Recife, Natal e Porto Alegre, para citar alguns exemplos (ALMEIDA, 2012).

Conforme Correia (2008), as formas escalonadas, geométricas e/ou arredondadas, características desse período, diluem-se em duas principais vertentes, conhecidas pelo meio científico como o zigzag modern e o streamlined. No primeiro caso, nota-se elementos que aproximam o Art Déco ao que posteriormente ficou conhecido como o racionalismo modernista, apresentando linhas e ângulos retos na forma de frisos, elementos escalonados e/ou em ziguezague, principalmente na platibanda e em torno das esquadrias. Em tais edificações, geralmente, o acesso principal é centralizado e as marquises e sacadas são retilíneas e imprimem sensação de pureza e simplicidade formal (Figura 2).

Figura 2: Edificação Art Déco em Passo Fundo com características que remetem ao zigzag modern, sendo elas: 1 - platibanda reta e escalonada; 2 - frisos lineares; 3 - marquises retilíneas; 4 - volumes retos e simples nas sacadas; e 5 - acesso principal centralizado, mesmo que um pouco deslocado para a esquerda.

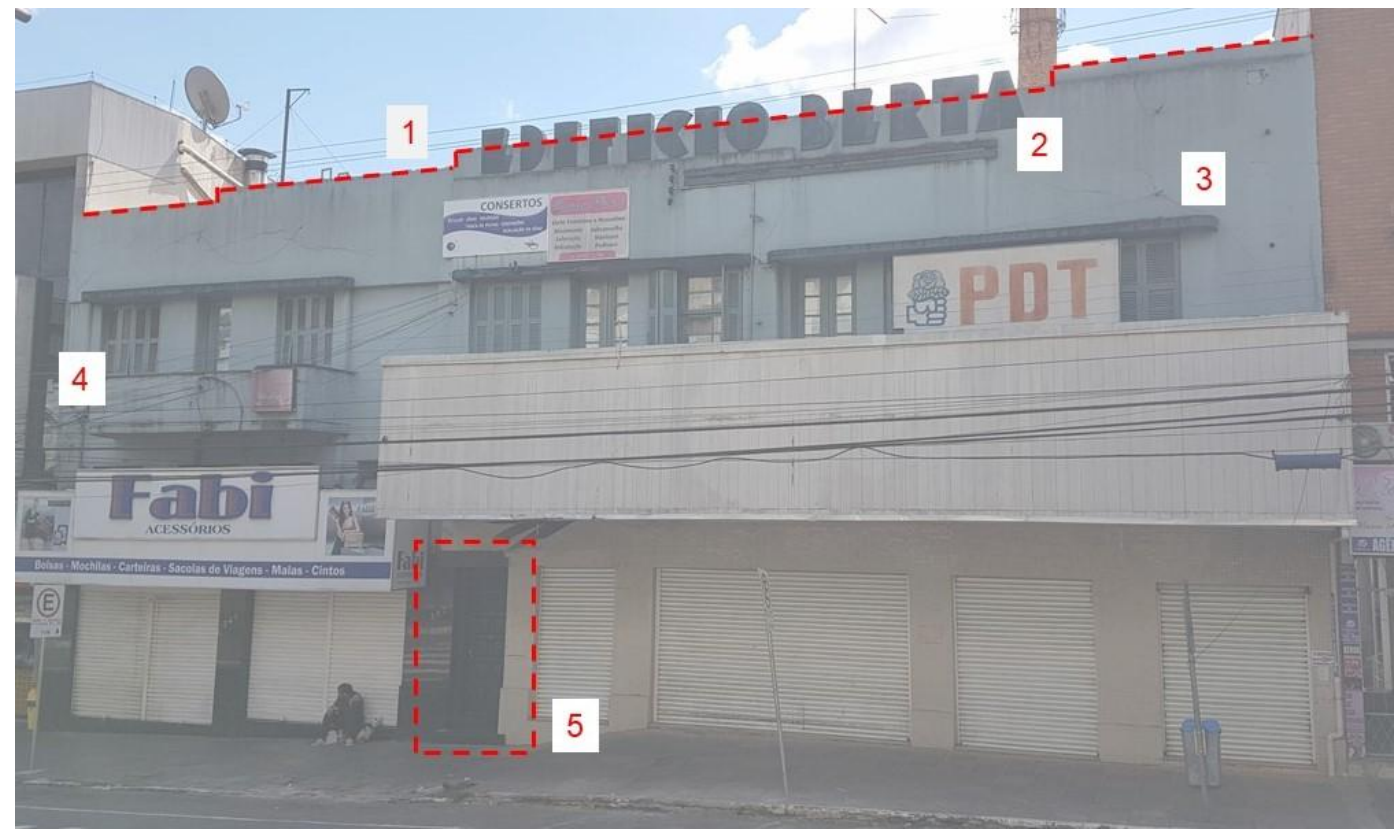

Fonte: Acervo pessoal (2019). Edição própria, 2020. 
Por outro lado, os prédios com referências ao streamlinded (Figura 3) possuem formas mais curvas e aerodinâmicas. As platibandas, marquises, sacadas e frisos são, via de regra, arredondados. Por esse motivo, grande parte das edificações com essas características foram construídas em esquinas, que eram demarcadas pelas formas curvas e pelo acesso principal. Em muitos casos, algumas janelas também eram construídas em forma de óculo (circular), fazendo alusão às janelas dos navios (CORREIA, 2008).

Figura 3: Edificação Art Déco em Passo Fundo com características que remetem ao streamlined, sendo elas: platibanda, marquise, parede e sacada curvas (números 1, 2, 3 e 5); colunas e suporte para mastro de bandeira (números 6 e 4); e gradil com perfis de ferro circulares (número 7). Nota-se que, neste caso, todos os elementos circulares da casa, somados às colunas e ao mastro, ajudam a demarcar a esquina.

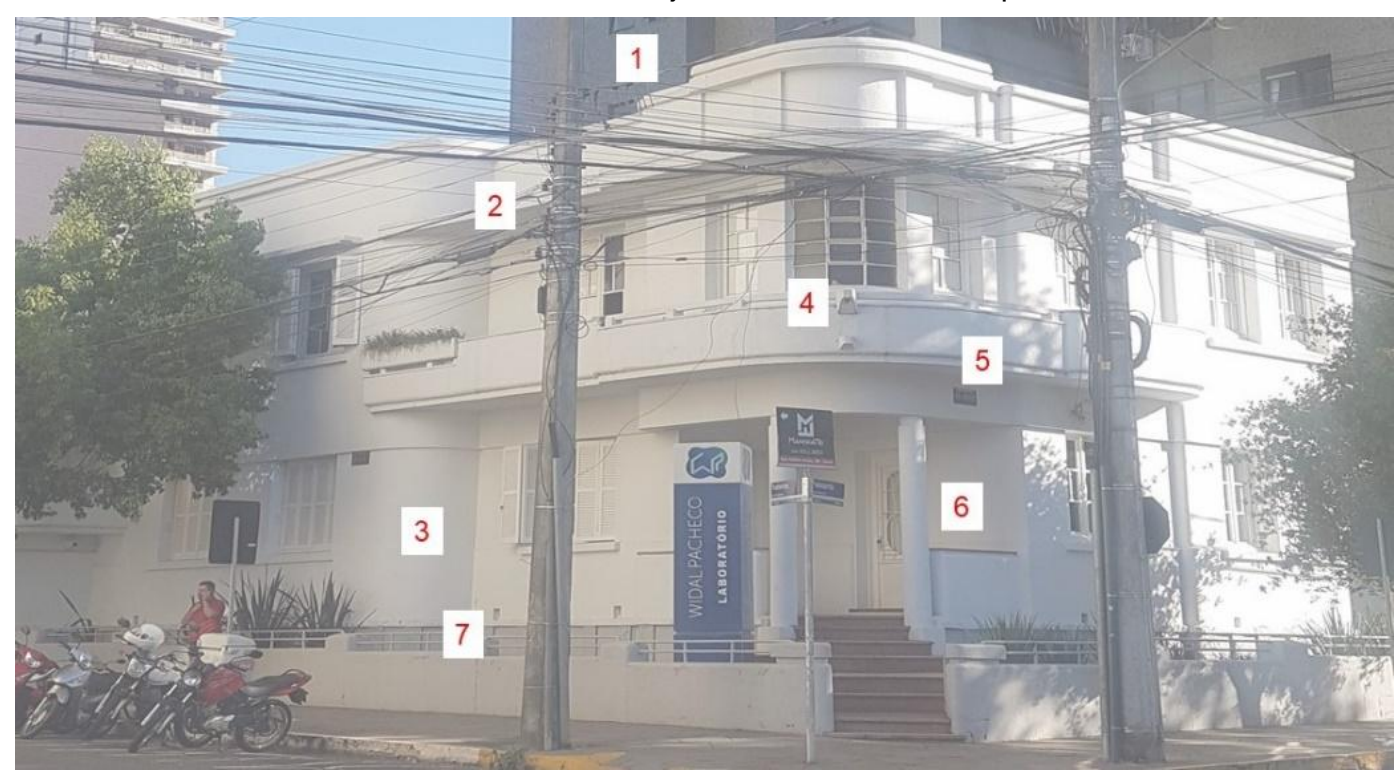

Fonte: Acervo pessoal (2019). Edição própria, 2020

Como pode-se perceber nos exemplos supracitados, as platibandas foram largamente empregadas no coroamento das fachadas e, em muitos casos, possuíam relevos geométricos com frisos, comportando-se como um prolongamento da parte externa dos prédios. No sul do país, essas referências arquitetônicas encontraram largo campo de aceitação, sendo facilmente identificadas em cidades de grande e médio porte, a exemplo de Passo Fundo.

\subsection{Passo Fundo e a expressividade Art Déco}

O município de Passo Fundo possui aproximadamente 200 mil habitantes (IBGE, 2010), sendo caracterizado como de porte médio graças aos tipos de relações horizontais e verticais que apresenta com municípios próximos e outros estados brasileiros (FERRETTO, 2012). O agronegócio e a indústria alimentícia formam um complexo agroindustrial na cidade, responsável pela maior parte das relações verticais estabelecidas. Já os serviços de saúde, educação e o comércio se configuram como os principais vetores de atração para a população de diversas cidades do noroeste gaúcho, firmando as relações horizontais (Figura 4). 
Figura 4: Mapa de localização da cidade de Passo Fundo, ao noroeste do estado do Rio Grande do Sul.

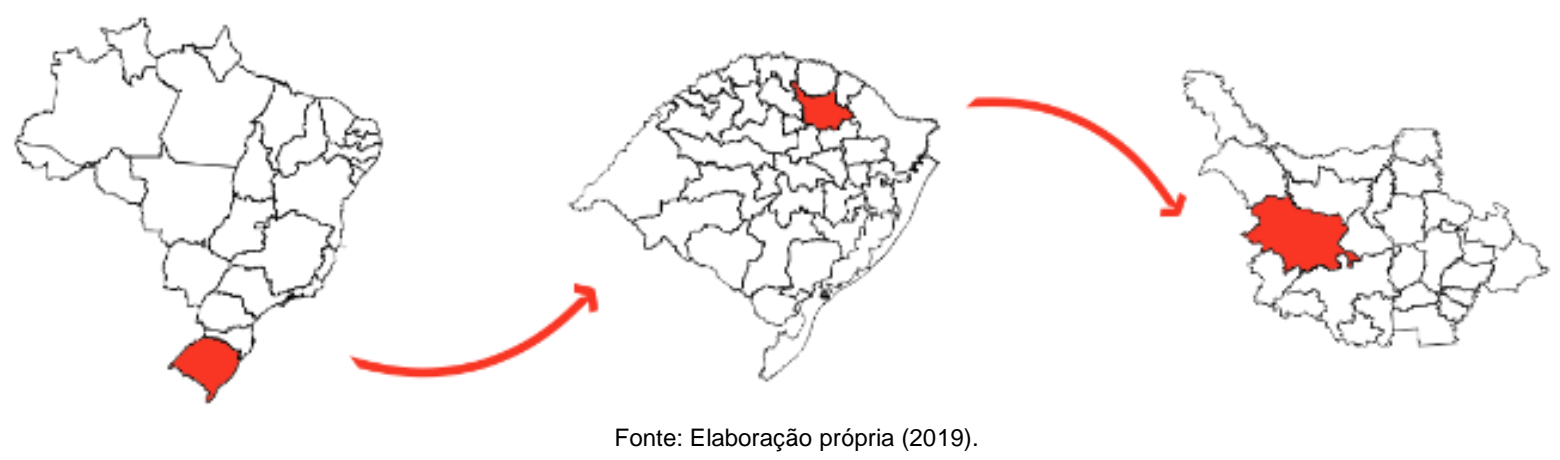

O processo de ocupação da região onde atualmente está localizada a cidade de Passo Fundo data das primeiras décadas do século XIX. Naquela época, o território servia principalmente como passagem dos tropeiros - condutores de tropas e de alimentos, principalmente charque (carne seca) - do sul do estado do Rio Grande do Sul para a região sudeste do país, em especial São Paulo. Esse trajeto ficou conhecido como Estrada de Tropas e hoje se conforma como a principal via arterial da cidade de Passo Fundo: a Avenida Brasil (PARIZZI, 1983; FERRETTO, 2012).

Após a primeira fase de expansão urbana, impulsionada pela construção da linha férrea Tronco Norte Gaúcha, em fins do século XIX e início do século XX, Passo Fundo se desenvolveu economicamente e se transformou em um polo regional, com destaque para os setores da agricultura e pecuária, comércio e serviços (PARIZZI, 1983). Foi diante desse cenário de crescimento econômico e a exemplo do que estava acontecendo nos grandes centros urbanos brasileiros, salvo as devidas proporções, por volta dos anos 1930 e 1940, que começou a se edificar e disseminar a arquitetura com referências ao Déco na cidade.

O primeiro exemplar Art Déco construído em Passo Fundo foi o Edifício Lângaro (Figura 5), que data de 1942, e está localizado na esquina da Avenida Brasil com a Avenida General Neto, na região central da cidade. O mencionado edifício foi projetado pelo engenheiro Annito Petry e também se configura como o primeiro prédio residencial de apartamentos da cidade (GOSCH, 2002). Pode-se dizer, assim, que o Edifício Lângaro marcou o início do processo de verticalização da área central passofundense. Levantamentos pretéritos revelam que Passo Fundo chegou a comportar mais de 200 edificações com referência Déco ao longo das décadas de 1940 a 1960 (LORENZI, GONÇALVES e PICCINATO, 2018). 
Figura 5: Edifício Lângaro atualmente (2020).

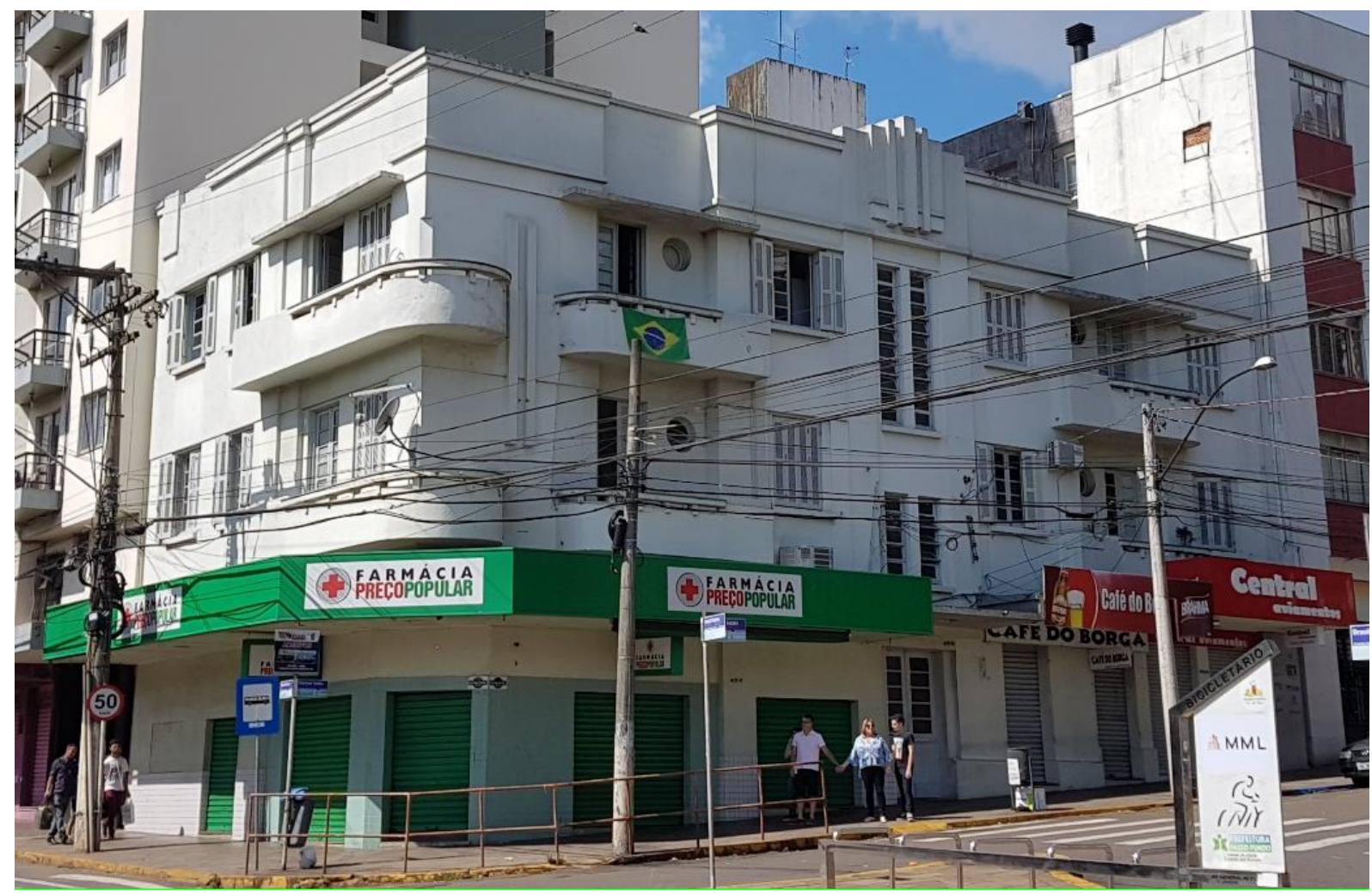

Fonte: acervo pessoal, 2019.

Naquele período, o centro de Passo Fundo se desenvolvia entre a Avenida Brasil e a Estação Ferroviária, tendo a Avenida General Neto como principal eixo de conexão (Figura 6). Além dessas, outras vias importantes também se destacavam, a exemplo das Ruas Morom, Independência e Bento Gonçalves, que abrigavam os principais espaços coletivos e de lazer e os mais tradicionais estabelecimentos comerciais e de serviço da cidade. Nessa área central também estavam situados antigos casarões neocoloniais e ecléticos, ocupados pelas famílias mais abastadas, que frequentavam os clubes, cafés e cinemas no centro da cidade (GOSCH, 2002; FERRETTO, 2012). Por estas especificidades que a área estudada neste artigo foi delimitada.

Ao analisar o mapa da cidade (Figura 6), percebe-se que a maioria dos exemplares Art Decó identificados estão localizados justamente entre a Avenida Brasil e a Estação Ferroviária, demonstrado que a arquitetura com características Art Déco esteve muito presente no desenvolvimento da centralidade urbana de Passo Fundo a partir de meados do século XX. 
Figura 6: Delimitação da área estudada no centro de Passo Fundo e mapeamento das 42 edificações Art Déco identificadas, com ênfase nas 6 selecionadas para análise de fachada neste artigo.

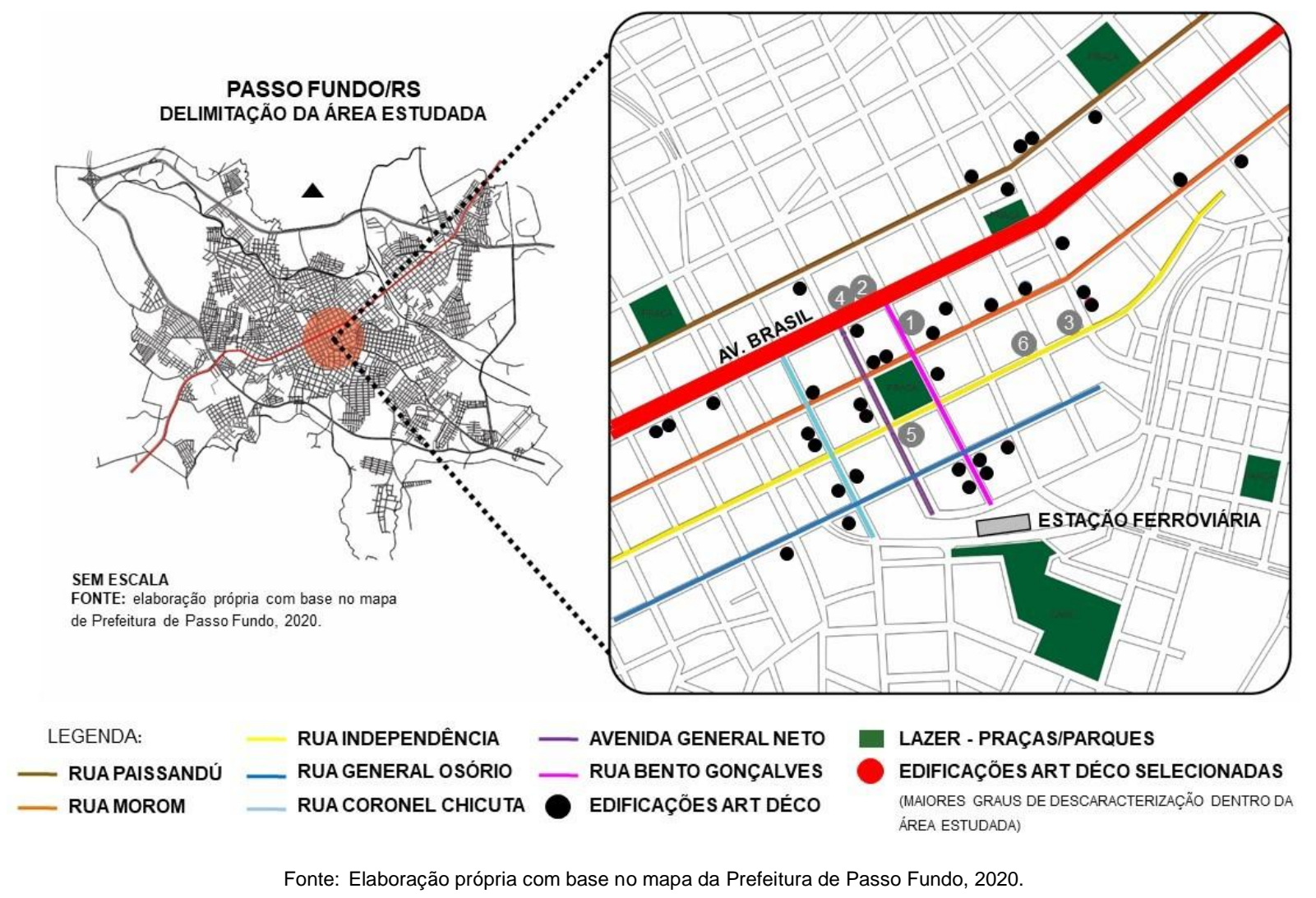

Por mais que o Art Déco tenha feito parte da construção do habitat moderno em Passo Fundo, marcando inclusive o processo de verticalização da cidade, nenhuma das 42 edificações identificadas neste artigo é tombada ou possui qualquer tipo de proteção legal. Ademais, não há nenhum projeto de lei municipal que preveja a padronização das placas, letreiros, outdoors, cores ou revestimentos das edificações históricas da cidade, para incentivar o resguardo das características arquitetônicas originais destas construções. Sendo assim, pode-se dizer que o valor histórico e cultural do Art Déco em Passo Fundo está sendo negligenciado pela municipalidade e pela população, que desconhece o seu papel no processo de modernização da cidade; ficando o repertório relegado aos interesses da iniciativa privada e correndo risco de desaparecer.

Durante as visitas in loco e análises subsequentes, pôde-se perceber diversos fatores agravantes que estão comprometendo as características arquitetônicas pertencentes ao vocabulário Decó e, por vezes, a identidade dos prédios mapeados. Aproximadamente 31 edificações $(73,8 \%)$ apresentam algum tipo de alteração proveniente da atividade publicitária. Destas, 15 construções estão significativamente descaracterizadas $(35,7 \%$ do montante total). Para demonstrar alguns dos danos mais comuns observados, elencou-se 6 edificações que se encontram comprometidas por objetos publicitários, para análise (Figuras 7, 8 e 9). 
Figura 7: Edificações ํํ 1 e ํํㄴ 2 que apresentaram alterações significativas provenientes da atividade publicitária.

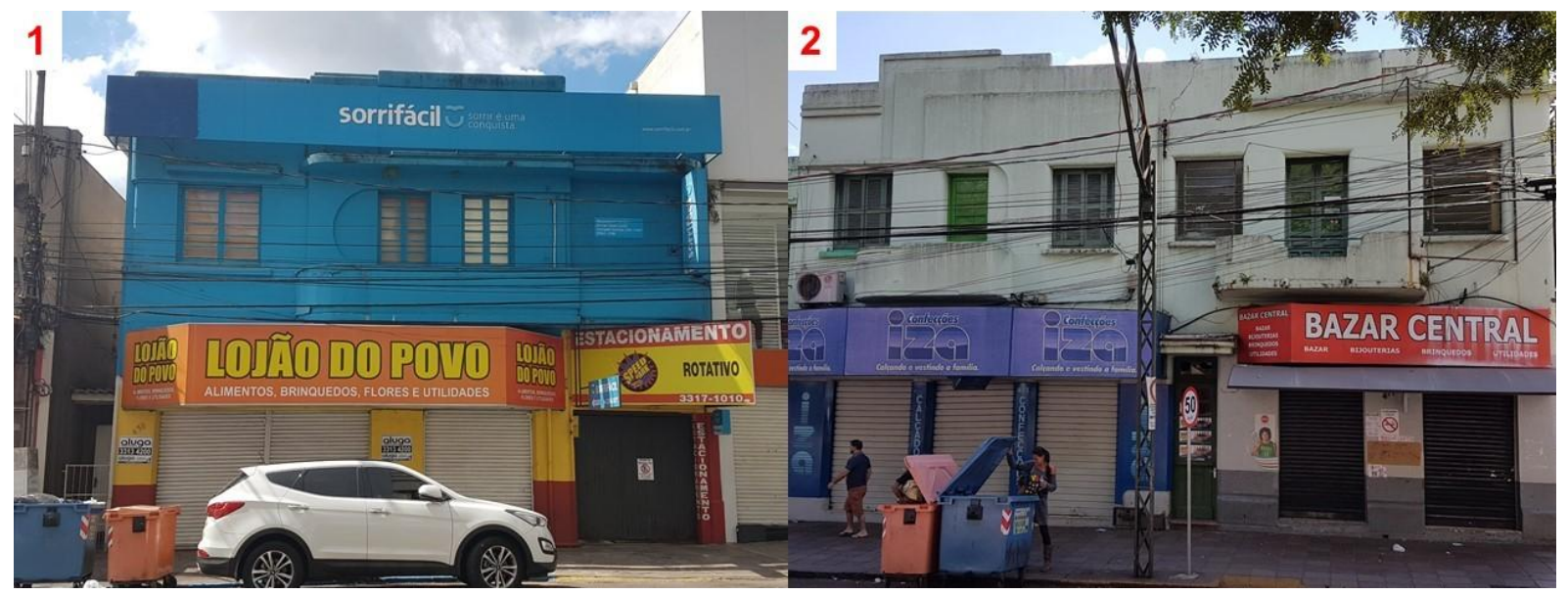

Fonte: Acervo pessoal (2019). Edição própria, 2020.

Edificação no 1: localizada na Rua Bento Gonçalves, n 459, Bairro Centro. Trata-se de um prédio com dois pavimentos, de uso originalmente misto, sendo comercial no pavimento térreo e residencial no segundo. Atualmente, o prédio abriga um estacionamento rotativo, uma loja de utilitários domésticos e uma clínica dentária. Em linhas gerais, essa edificação possui características que remetem ao streamlined, devido aos elementos arredondados presentes em sua volumetria, principalmente na sacada, na marcação das janelas e nas marquises. Como pode-se perceber, os letreiros são demasiadamente grandes e não seguem nenhuma padronização ou harmonização - seja em relação à forma, à cor ou ao material utilizado -, impossibilitando, também, a identificação dos elementos de grande parte do térreo e do coroamento da edificação. Ademais, as cores da fachada foram alteradas e destoam entre o primeiro e o segundo pavimento.

Edificação no 2: localizada na Avenida Brasil (oeste), № 434, Bairro Centro. Trata-se de um prédio com dois pavimentos, cujo uso original - misto - se mantém até os dias de hoje: uma loja de confecções e um bazar no pavimento térreo e dois apartamentos no segundo pavimento. Assim como no exemplo anterior, essa edificação remete às características do streamlined, devido às sacadas e às marcações arredondadas nas esquadrias. Nesse caso, as placas dos estabelecimentos também não seguem nenhum tipo de padrão, destoam entre si e, em virtude do tamanho, impossibilitam a identificação dos elementos que compõem grande parte da fachada.

Figura 8: Edificações № 2 e ํํ 3 que apresentaram alterações significativas provenientes da atividade publicitária.

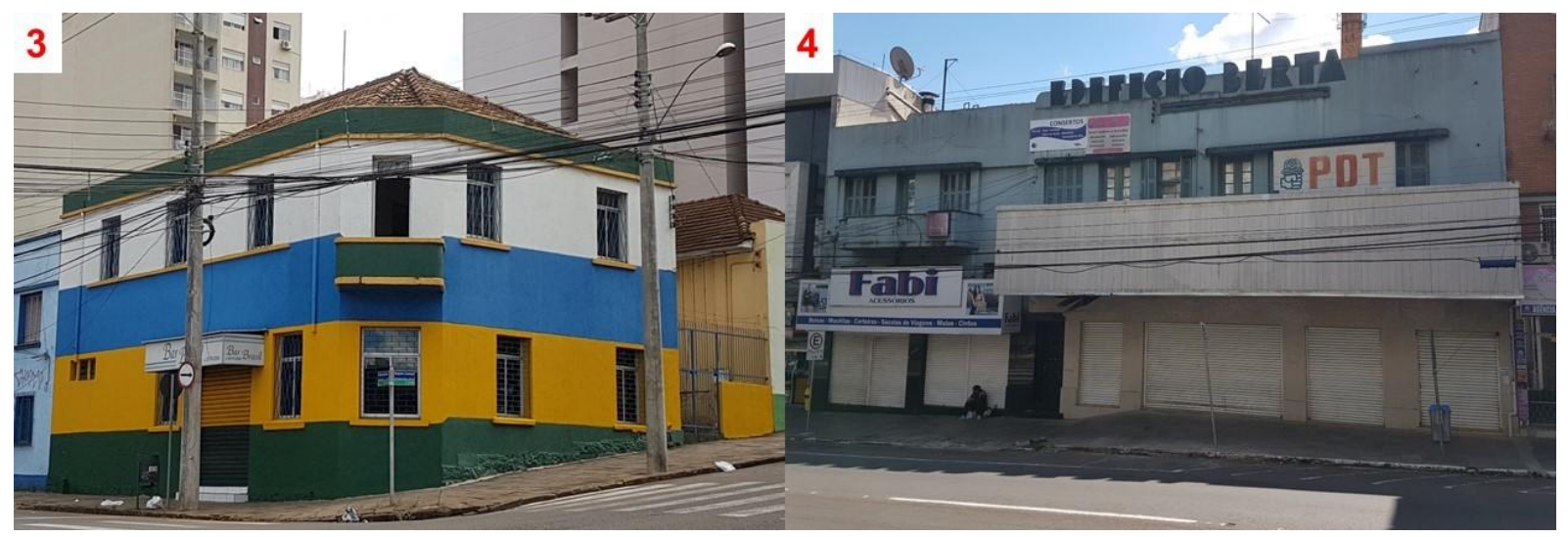

Fonte: Acervo pessoal (2019). Edição própria, 2020. 
Edificação no 3: localizada na Rua Independência, № 225, esquina com a Rua Benjamin Constant, Bairro Centro. Mais uma vez, trata-se de um prédio de dois pavimentos de uso originalmente misto, fato que se mantém até a atualidade com um bar no pavimento térreo e uma residência unifamiliar no segundo pavimento. As características volumétricas remetem ao zigzag modern, apresentando linhas mais retas e maior simplicidade formal. Nesse caso, a placa fixada no acesso do bar não é desproporcional ao prédio, mas as cores aplicadas no revestimento das fachadas evidenciam um tratamento publicitário apelativo, beirando o Kitsch, uma vez que o estabelecimento se chama "Bar Brasil" e a paleta utilizada faz alusão à bandeira brasileira. Como verificado na legislação anteriormente analisada, as cores empregadas nas edificações de valor histórico devem seguir um padrão coerente, destacando e facilitado a identificação dos elementos arquitetônicos das fachadas.

Edificação no 4: edificação localizada na Avenida Brasil, ํo 349, Bairro Centro. O Edifício Berta, originalmente de uso misto, atualmente é utilizado apenas para uso comercial. As características volumétricas remetem ao zigzag modern, devido ao escalonamento da platibanda e às linhas retas presentes nos frisos, na sacada e no próprio letreiro com o nome do prédio. Em virtude da mudança de uso, percebe-se a utilização de revestimentos destoantes entre o térreo e o pavimento superior, que ainda preserva características originais. Além disso, percebe-se a fixação de anúncios publicitários despadronizados e que cobrem demasiadamente a fachada, em especial a sala comercial desocupada.

Figura 9: Edificações № 5 e № 6 que apresentaram alterações significativas provenientes da atividade publicitária.

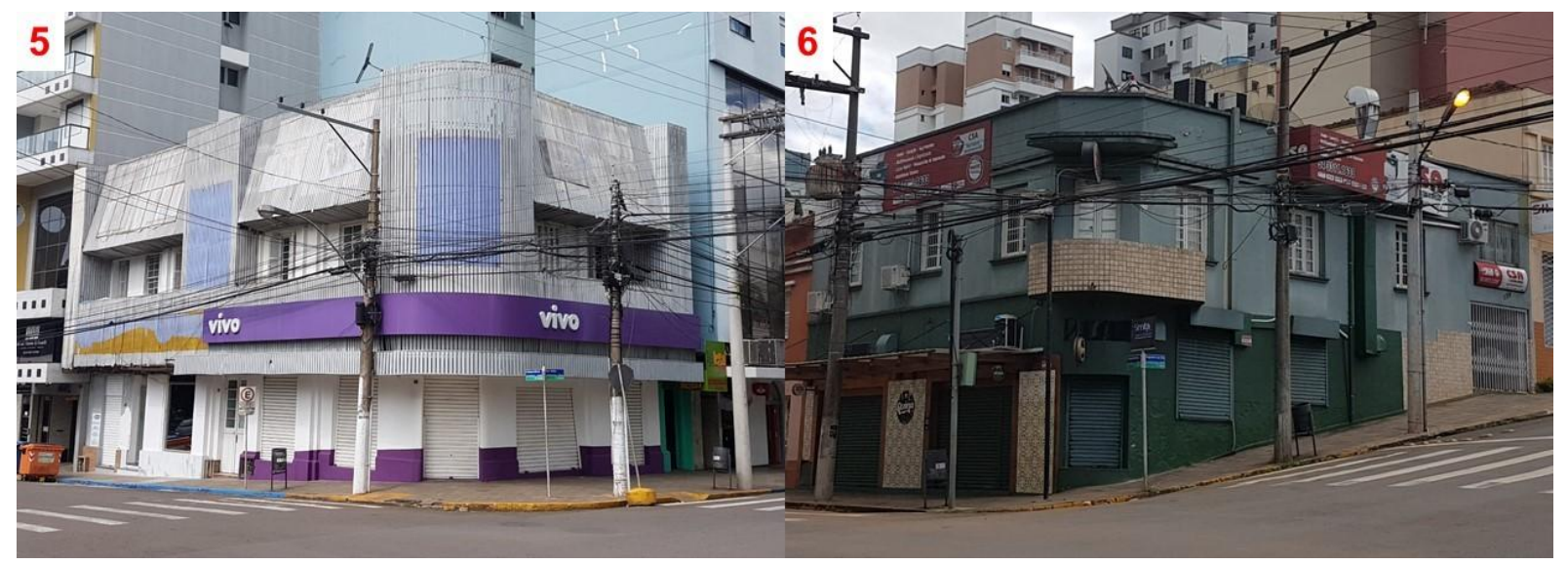

Fonte: Acervo pessoal (2019). Edição própria, 2020

Edificação no 5: edificação localizada na Rua Independência, no 700, esquina com a Avenida General Neto, Bairro Centro. Originalmente de uso misto, esse prédio está totalmente ocupado por uma loja de telefonia móvel. A marcação da esquina com o acesso principal, bem como as formas mais arredondadas da volumetria externa remetem à vertente arquitetônica streamlined. Entretanto, como pode-se perceber, praticamente $2 / 3$ das fachadas foram cobertos por um ripado que faz parte da identidade visual da empresa, impossibilitando a identificação de quase todos os elementos arquitetônicos.

Edificação no 6: edificação localizada na Rua Independência, no 337, esquina com a Rua Fagundes dos Reis, Bairro Centro. Seu uso original - comercial e residencial (misto) -, foi modificado e atualmente o prédio abriga um PUB noturno no primeiro pavimento e uma gráfica no segundo. Assim como no exemplo anterior, verifica-se a marcação da esquina com o acesso principal, bem como algumas formas mais arredondadas em elementos como a sacada e a marquise, fatores que remetem ao streamlined. Devido aos seus diferentes usos, nota-se a utilização de materiais destoantes entre o térreo e o pavimento superior, além da anexação de anúncios destoantes em tamanho, cor e forma. 
Esses são, portanto, seis exemplos que demonstram a necessidade de um olhar mais cauteloso em relação à preservação dos prédios históricos, essencialmente aqueles que remetem ao léxico Déco, inseridos na malha urbana passofundense. Vale mencionar que, com exceção do Edifício Berta, os letreiros com os nomes dos outros cinco exemplares não puderam ser identificados, pois foram retirados das fachadas e/ou cobertos pelos anúncios publicitários.

Observando por outro viés, verificou-se também bons exemplos de tratamento publicitário e conservação dentre as edificações Art Déco identificadas. Mais precisamente, 11 prédios (aproximadamente $26,2 \%$ do total) estão em bom estado de conservação e, no caso de edificações comerciais ou de serviço, possuem placas e anúncios em tamanhos e cores que não comprometem a percepção dos elementos arquitetônicos originais e podem servir de exemplo no âmbito da cidade de Passo Fundo (Figura 10).

Figura 10: Montagem com os 11 exemplares Art Déco que apresentaram os menores problemas de identidade provenientes da prática publicitária e/ou do seu estado de conservação.

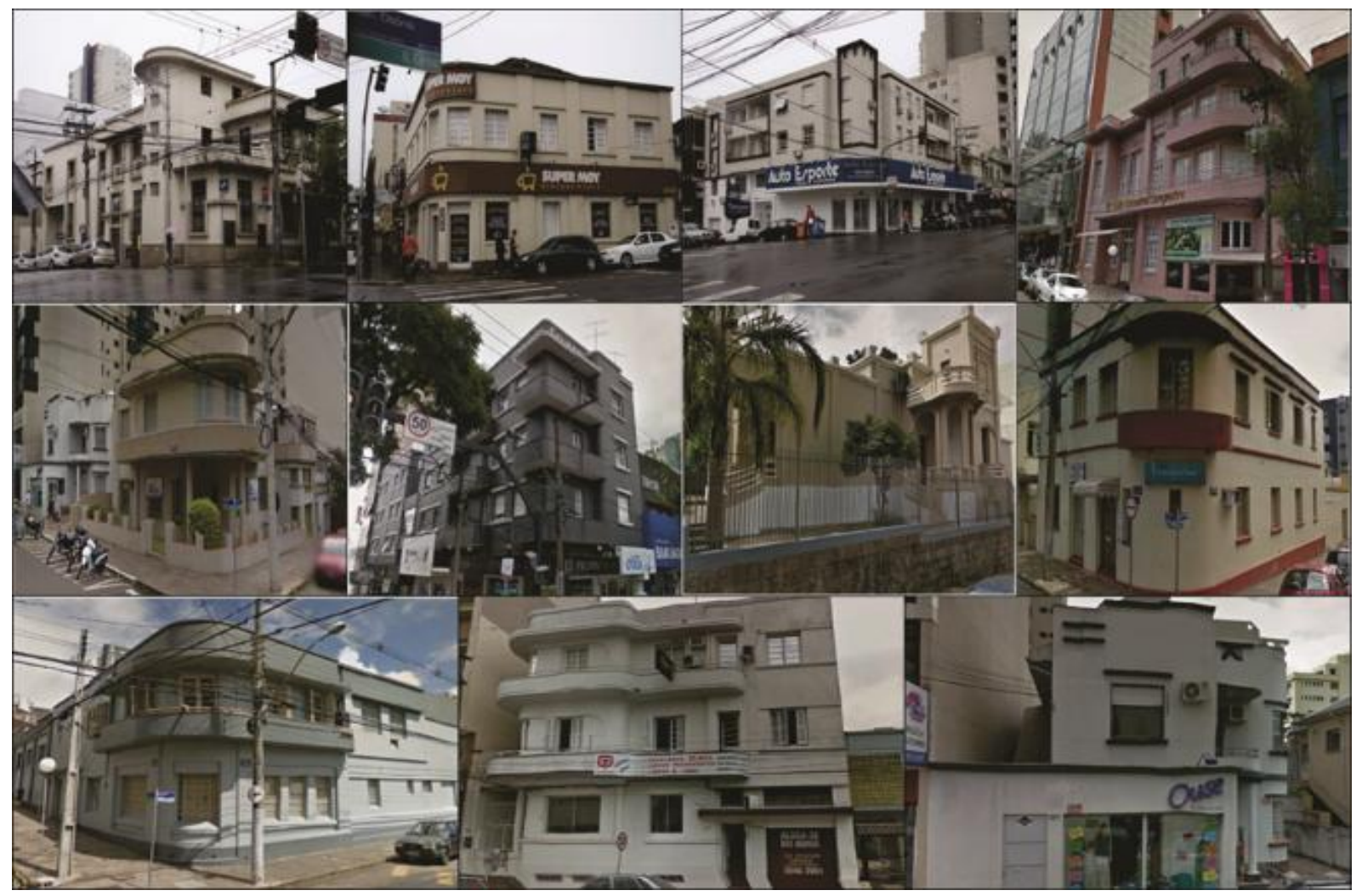

Fonte: Acervo pessoal (2019). Edição própria, 2020

\section{Considerações finais}

O Art Déco pode ser percebido em muitas lojas de departamentos, postos de gasolina, cinemas, clubes, fábricas e residências edificadas ao longo da primeira metade do século XX, podendo ser considerado como um movimento arquitetônico que deu início ao processo de modernização de diversas cidades brasileiras, refletindo um novo modo de morar e alterando a paisagem urbana. No caso de Passo Fundo, as edificações apresentadas neste artigo deveriam ter seu valor histórico reconhecido por parte do poder público e da população, pois fazem parte de um conjunto arquitetônico com características Art Déco expressivo, datado de meados do século XX, que ajudou a construir o habitat moderno da cidade. Além disso, os prédios identificados foram concebidos durante um importante período de expansão da malha urbana e modernização da cidade, época na qual as técnicas construtivas e os materiais utilizados eram diferentes. 
Acredita-se no reuso como uma das formas de preservação das edificações de valor histórico, por mais que algumas concepções acerca deste assunto sejam divergentes. Entretanto, no Brasil, o problema social e urbano associado ao patrimônio e a forma como este é reabilitado para uma nova função está vinculado à falta de conscientização geral dos proprietários das edificações, da população que as utiliza e do poder público. Como visto anteriormente, a atividade publicitária tem causado danos às construções de valor histórico e cultural, contribuindo para a poluição visual das cidades e comprometendo a qualidade da paisagem urbana dos centros históricos.

Grande parte do repertório Déco identificado em Passo Fundo, no tocante aos estabelecimentos comerciais e de serviço, possui placas e anúncios excessivamente grandes e desproporcionais, além de pinturas e revestimentos destoantes, comprometendo as fachadas e interferindo significativamente na percepção da identidade arquitetônica. Nesse sentido, assim como ocorre em muitas outras cidades, nota-se em Passo Fundo uma desvalorização da importância histórica e cultural dos prédios Art Déco em detrimento ao valor seu material e econômico, deixando a sua gestão a cargo dos interesses da iniciativa privada. Por outro lado, como visto nos casos de São Paulo, Erechim e Bento Gonçalves, a municipalidade tem o poder de ditar as regras para a atividade publicitária, em especial quando se trata dos centros históricos das nossas cidades.

Por fim, vale mencionar que Erechim era distrito de Passo Fundo até o ano de 1918 (PARIZZI, 1983). Entretanto, mesmo após a emancipação, muitas características arquitetônicas e urbanísticas são comuns entre as duas cidades, inclusive a expressividade do Art Déco. Desse modo, indica-se a mencionada lei "Erechim, Cidade Limpa", como exemplo basilar para a criação de uma lei municipal específica que disponha dos tamanhos, cores e formas dos anúncios publicitários em edificações históricas de Passo Fundo, além de ações voltadas à educação patrimonial na cidade. Portanto, cabe ao poder público, bem como aos arquitetos e urbanistas e aos demais profissionais da construção civil e da publicidade, discutirem formas de se conciliar a salvaguarda das construções históricas com a prática da propaganda, tão presente e necessária nos dias atuais.

\section{Agradecimentos}

À Coordenação de Aperfeiçoamento de Pessoal de Nível Superior (CAPES) e à Fundação Meridional pelas bolsas concedidas.

\section{Referências}

ALMEIDA, Caliane Christie Oliveira de. Habitação social no Nordeste: a atuação das CAPs e dos IAPs (1930-1964). 2012. Tese (Doutorado em Teoria e História da Arquitetura e do Urbanismo) - Instituto de Arquitetura e Urbanismo, Universidade de São Paulo, São Carlos, 2012. doi:10.11606/T.102.2012.tde12042013-101921. Acesso em: 2019-06-15.

ALMEIDA, Caliane Christie Oliveira de. Habitação social: origens e produção (Natal, 1889-1964). 2007. Dissertação (Mestrado em Teoria e História da Arquitetura e do Urbanismo) - Escola de Engenharia de São Carlos, Universidade de São Paulo, São Carlos, 2007. doi:10.11606/D.18.2007.tde-01122007140621. Acesso em: 2019-06-15.

AMBRÓSIO, Mariana Rodrigues; ZALITE, Marcela Gomes de Albuquerque. Identificação estética e de comunicação das fachadas de lojas comerciais: um estudo na Avenida Brasil em Maringá. Revista de Iniciação Científica da Unifamma, v. 3, n. 1, p.1-18, 2018.

BENTO GONÇALVES, Lei ํㅜ 5871, de 24 de novembro de 2014. Dispõe sobre a publicidade e propaganda no perímetro urbano do município de Bento Gonçalves e dá outras providências. Secretaria do Governo Municipal, publicado em 24 de novembro de 2014. 
BRENNER, Ariana Souto; MAROSTEGA, Valéria Rolim; ALMEIDA, Caliane Christie Oliveira de. Poluição visual e o ambiente construído: programa Anuncie Legal como instrumento de padronização na comunicação visual. In: XI Mostra de Iniciação Científica e Extensão Comunitária e X Mostra de Pesquisa de Pós-Graduação IMED, 2017.

CITRON, Rafaela Simonato; MENDES, Aline de Oliveira; TALAMINI, Josiane. Patrimônio Art Déco em Carazinho/RS: reconhecimento, valorização e preservação. Gestão e Gerenciamento, [S.I.], v. 1, n. 8, p. 26 - 35, abr. 2018.

CORREIA, Telma de Barros. Art déco e indústria: Brasil, décadas de 1930 e 1940. Anais do Museu Paulista: História e Cultura Material, v. 16, n. 2, p. 47-104, 2008.

ERECHIM, Lei oㅜ 6.093, de 22 de dezembro de 2015. Regulamenta a instalação de anúncios em prédios e veículos e estabelece padrão de cores nos edifícios históricos do Município de Erechim. Secretaria do Governo Municipal, publicado em 22 de dezembro de 2015.

FERRETTO, Diego. Passo Fundo: estruturação urbana de uma cidade média gaúcha. 2012. Dissertação (Mestrado em Planejamento Urbano e Regional) - Faculdade de Arquitetura e Urbanismo, Universidade de São Paulo, São Paulo, 2012. doi:10.11606/D.16.2012.tde-17072012-143123. Acesso em 15 jun. 2019.

FOGAÇA, Paula. Patrimônio e paisagem cultural: a imigração italiana em Veranópolis/RS- Brasil. 2019. Dissertação (Mestrado em Arquitetura e Urbanismo) - Escola Politécnica, Faculdade Meridional, Passo Fundo, 2019. Acesso em 24 mai. 2020.

GOMES, Rosany Rossi Pereira et al. PERCEPÇÃO DA POLUIÇÃO VISUAL NO CENTRO URBANO DE MOSSORÓ/RN. Revista Geotemas, v. 9, n. 1, p. 49-69, 2019.

GOSCH, L. R. M. Passo Fundo, de Saturnino de Brito ao Mercosul - projetos e imagens urbanas. (Dissertação). Rio de Janeiro: FAU/UFRJ, 2002.

INSTITUTO BRASILEIRO DE GEOGRAFIA E ESTATístICA - IBGE. Censo Demográfico. Passo Fundo/RS, 2010. Disponível em: < http://cidades.ibge.gov.br/xtras/perfil.php?codmun=431410/ >. Acessado em 17 de agosto de 2018.

LECH, Osvandré; CZAMANSKI, Deoclides; CZAMANSKI, Ronaldo. Passo Fundo: memória e fotografia. 2. ed. Passo Fundo: Pe. Berthier, 1999.

LORENZI, L. R.; GONÇALVES, A. S.; PICCINATO JUNIOR, D. Percepção do usuário: Art Déco e o Edifício Lângaro em Passo Fundo - RS. In: XII Mostra de Iniciação Científica e Extensão Comunitária e XI Mostra de Pesquisa de Pós-Graduação IMED 2018, 2018, Passo Fundo. Anais do..., 2018.

LORENZI, L. R.; PICCINATO JUNIOR, D. Entre memória e história: la arquitectura Art Déco y el no reconocimiento de su valor histórico en la ciudad de Passo Fundo/RS, Brasil. In: $2^{\circ}$ Congreso Iberoamericano de História Urbana Procesos históricos que explican la ciudad iberoamericana, 2019, Ciudad de México. Anais do..., 2019.

MACHADO, Ironita P.; MIRANDA; Fernando B. S. Passo Fundo: presentes da memória. Rio de Janeiro: MM Comunicação, 2005.

NASCIMENTO, Flávia Brito do. Blocos de memórias: habitação social, arquitetura moderna e patrimônio cultural. 2011. Tese (Doutorado em Habitat) - Faculdade de Arquitetura e Urbanismo, Universidade de São Paulo, São Paulo, 2011. doi:10.11606/T.16.2011.tde-11012012-100337. Acesso 
em: 2020-05-24.

PARIZZI, Marilda Kirst. Passo Fundo: sua história e evolução. Passo Fundo: Berthier, 1983.

PISSETTI, R. F.; SOUZA, C. F. Art Nouveau e Art Déco: confluências. Revista Imagem, Caxias do Sul, v. 1, n. 1, p. 17-24, 2011.

PORTAL DA PREFEITURA DE SÃO PAULO. São Paulo recebe prêmio europeu em reconhecimento à Lei Cidade Limpa. São Paulo, 2012. Disponível em:

< http://www.prefeitura.sp.gov.br/cidade/secretarias/comunicacao/noticias/?p=107970 >. Acessado em 13 de fevereiro de 2020.

SALVADOR, Sabrina Carnin. As edificações Art Déco na paisagem urbana: um estudo de caso em Criciuma - SC. 2012. 138 p. Dissertação (Mestrado em Arquitetura e Urbanismo) - Faculdade de Arquitetura e Urbanismo, Universidade Federal de Santa Catarina, Florianópolis, 2012.

SANTOS, Gilmar. Princípios da publicidade. Editora UFMG, 2005.

SÃO PAULO, Lei no 14.223, de 26 de setembro de 2006. Dispõe sobre a ordenação dos elementos que compõe a paisagem urbana do município de São Paulo. Secretaria do Governo Municipal, publicado em 26 de setembro de 2006.

SILVA, Daniela Regina da; LOPES, Jairo de Araújo. Publicidade no Brasil: novos caminhos, novas linguagens. Revista de Ciências Humanas, v. 41, n. 1 e 2, p. 157-178, 2007.

TIRELLO, R. A.; COSTA, A. C. S. Questões sobre conservação do patrimônio arquitetônico moderno e a Vila Serra do Navio. PARC Pesquisa em Arquitetura e Construção, v. 8, n. 2, p. 75-87, 30 jun. 2017.

VENTURINI, A; LIMA, Raquel Rodrigues. Modernidade na tengente: edifícios de apartamentos Art Déco em Porto Alegre. Salão de Iniciação Científica PUCRS, 10. 2009, Porto Alegre. In: Anais do X Salão de Iniciação Científica PUCRS, Porto Alegre, 2009, p. 1862-1866. 